\title{
Professionalism, then and now
}

\author{
P. R. H. Newsome ${ }^{* 1}$ and P. P. Langley ${ }^{2}$
}
IN BRIEF
- Describes how the meaning of professionalism has changed in recent years.
- Explains current issues and concerns regarding professionalism in dentistry.
- Highlights professionalism and business success are not mutually exclusive, rather they complement each other.
- Stresses that everyone in an organisation contributes to the overall sense of professionalism.

For centuries only three professions were recognised as such: medicine, law and theology. Now that the word 'professional' is applied to all occupations it can be difficult to understand the meaning of professionalism within dentistry and healthcare. We simply cannot treat dentistry as a commodity or business when it is a highly specialised personal service. Now more than ever, dentistry is a team game and all dental professionals must maintain the values and codes that distinguish what we do from most other vocations.

\section{INTRODUCTION}

As dentists, we are rightly proud of the fact that we belong to a well-established, well-respected profession but what exactly constitutes a profession and what does it mean, in 2014, to be a 'professional'? This article looks at the defining characteristics of a profession, explores how dentistry acquired this mantle, examines the ways it has, in recent years, moved away from traditional notions of professionalism and considers whether all the various changes that have taken place have been in the best interests of both dentists and their patients.

In recent times, it seems that the epithet 'professional' has been applied to every type of occupation. Coffee shops extol the virtues of their 'professional baristas' and advertising is replete with messages from 'professional' decorators, 'professional' freight movers, 'professional' car sales people and so on. Consumers with a complaint often criticise every level of employee, from managing director to hotel receptionist, for 'unprofessional behaviour'. The word has perhaps been most notably misappropriated in the sporting arena where it has taken on a rather different meaning, primarily as the opposite of the amateur that is, someone who participates for the love of it. Use of the word in this context often implies an almost mercenary mindset and even one of cynicism as, for example, in 'professional foul.'

Level 19, Two International Finance Centre, 8 Finance Street, Hong Kong; ${ }^{2} 6$ Burnmoor Meadow, Finchampstead, Wokingham, RG40 3TX

*Correspondence to: P. R. H. Newsome

Email:newsome@hkucc.hku.hk

\section{Refereed Paper}

Accepted 15 January 2014

DOI: $10.1038 /$ sj.bdj.2014.355

${ }^{\circ}$ British Dental Journal 2014; 216: 497-502
For centuries, and before the word was hijacked in the manner described above, only three professions were recognised as such, namely medicine, law and theology (that is, the priesthood), the so-called 'learned professions'. Those engaged in these disciplines 'professed', or took an oath, before embarking into practice in the respective field. All other working people were either 'tradesmen' or 'labourers', with few exceptions. The butcher, the baker, and the candlestick maker were each members of individual and occupation-specific trade guilds. They served lengthy hands-on apprenticeships under a master before being initiated into the guild as a master themselves. Being a full member of a guild, having a 'trade', was a prestigious thing, worthy of respect in the community. There was no shame whatsoever in being 'non-professional', in being a 'tradesman'.

What set the learned professionals apart from 'mere' tradesmen was primarily the perception of them having direct control over the liberty, health and spiritual salvation of their customers, and hence even more respect. This certainly did not happen overnight. As far as medicine is concerned, the Royal Colleges of Surgeons of England can trace its roots as far back as 1368 with the foundation of the 'Guild of Surgeons Within the City of London'. Similarly, the Barber Surgeons of Edinburgh (later to become the Royal College of Surgeons of Edinburgh) were formally incorporated as a craft guild of the city in 1505 along with the granting of a charter of principles conferring various privileges as well as imposing certain crucially important, fundamental, duties, the most important being that all apprentices should be literate, that every master should have full knowledge of anatomy and surgical procedures and that this knowledge be tested at the end of the apprenticeship, all of which still apply to the college today.

Licensing soon followed in this chronology of events. In the case of doctors this process began as far back as 1421 when physicians petitioned parliament demanding that nobody without appropriate qualifications be allowed to practise medicine, accusing unqualified practitioners of causing 'great harm and the slaughter of many men.' In the first instance, somewhat bizarrely, parliament placed regulation of the medical profession in the hands of the Church, restricting the right of practice to only those deemed fit and worthy. This coincidentally, was of course of great financial benefit to those possessing the correct experience and qualifications. Excluding unqualified outsiders in this way has long been a feature of the professions.

The church largely oversaw the regulation of the UK medical profession for well over three centuries but by the mid-nineteenth century it was becoming obvious that they were totally ill-equipped to regulate the profession and to act to protect the public from false practitioners. Only governments had the wherewithal to create the necessary enforcement agencies and so licensure systems were initiated. In 1858 the right to grant entry into the profession was taken from the Royal Colleges to an agency of the government of the state, the General Medical Council (GMC) whose stated aim at the time was to enable "persons requiring medical aid to distinguish qualified from unqualified practitioners.'2 


\section{THE PROFESSION OF DENTISTRY}

Twenty years after the creation of the GMC, the 1878 British Dentists Act and 1879 Dentists Register limited the title of 'dentist' and 'dental surgeon' to qualified and registered practitioners. Paradoxically, others could legally describe themselves as 'dental experts' or 'dental consultants'. The British Dental Association, formed in 1880, played a major role in prosecuting dentists practising illegally. The practice of dentistry in the UK became fully regulated with the 1921 Dentists Act, ${ }^{3}$ which required the registration of anyone practising dentistry. This was entrusted to the Dental Board of the United Kingdom, which functioned under the auspices of the GMC. Many in the profession at this time were keen to break free from the GMC and in 1938 Sir Francis Dyke Acland, the first chairman of the Dental Board, expressed the view that: 'If the Council were to feel that the Board were sufficiently adult to be entrusted with an individual authority on any or all of the three subjects, discipline, registration and education, it would be wrong to continue by legislative enactment a connection which was always regarded as a stage in progress towards a more logical and satisfactory condition of things. ${ }^{4}$

This quote was referred to in the 1946 Teviot Report - the final report of the InterDepartmental Committee on Dentistry ${ }^{5}$ in which it was stated that there was very general agreement with the view that the Board was now 'sufficiently adult' and that the dental profession had earned the right to self-government. The Dentists Act of $1956^{6}$ enabled the realisation of those desires and as a result the General Dental Council (GDC) was born.

So, what exactly did a profession, be that dentistry, medicine or law, look and feel like back in the 1950s and 1960s? It quickly becomes apparent that there were certain shared characteristics behind all traditional professions and it is perhaps easiest to organise these characteristics under the headings below.

\section{Education}

Membership of any profession came only after the assimilation of knowledge and the attainment of high levels of specific skills. The marriage of a vocational skill with theoretical knowledge was an absolute pre-requisite for any professional. The very fact that such individuals possessed specialised, often unfathomable, skills mastered only after long, arduous periods of intense scholarly activity meant that lay people felt largely ill-equipped to pass judgement on such individuals. The very impenetrability of the skills required to practise law, medicine and so on, was largely the reason why professional institutions were allowed to maintain self-governing status.

\section{Self-determination}

Self-regulation was a fundamental and defining characteristic, so much so that outside interference was, wherever possible, avoided or kept to a minimum. In 1956, the newly-created General Dental Council comprised 43 members, including 11 dentists elected from the UK constituencies, 19 nominated by the dental authorities but only 4 lay members. Admittedly, this was an advance on the composition of the previous Dental Board, which was made up of 7 nominated and 6 elected dentists and no lay members whatsoever. Equally, all professions went to great lengths to determine who should be allowed to enter the fraternity and, just as significantly, who should not. This was reinforced by the rather polarised school system in place at the time. For example, The Royal Commission on Medical Education published in $1968^{7}$ found, for example, that in the early 1960s more than two thirds of medical students were male school leavers from white middle-class, professional backgrounds.

Few would argue that back in the 1950s professions were extremely conservative in nature and invariably resistant to change, especially when imposed from outside. While new ideas and approaches may not have been overtly discouraged the status quo was generally preferred and it usually took considerable time and a marked reluctance for them to be to be adopted.

\section{Discipline}

Members of the professions were expected to demonstrate consistently high levels of technical skill as well as compliance with a strict moral code underpinned by high levels of the following types of altruistic behaviour:

- Subjugation of one's own needs to those of others

- Treating others as you would wish to be treated

- Not letting personal issues get in the way of doing what is right

- A commitment to continued learning and excellence

- Never compromising one's standards and values

- An overriding compassion for others.

Once admitted to the inner sanctum, freshlyminted professionals were therefore expected not only to ply their trade competently (as defined by the regulatory institutions) but also to adopt and adhere to this wider set of beliefs and related codes of conduct. Woe betide anyone who might abuse such powers by behaving negligently or otherwise falling short in any way. These people would be judged by their peers and sanctioned accordingly. Permanent expulsion from the professional fraternity was, of course, the ultimate and most devastating of such punishments.

\section{Status}

The attributes just described imparted great status and prestige among members of a profession and it was clearly in the interests of these members therefore to maintain an aura of exclusivity, a certain mystique even. Accordingly, the relationship with lay people tended to be rather impersonal and distant, characterised by a sense of paternalism (doctor knows best) and in turn the public were expected to exhibit a certain deference towards professional people and were discouraged from questioning their skills and judgement. This was exemplified perfectly by the irascible chief surgeon Sir Lancelot Spratt as portrayed by James Robertson Justice in countless Doctor in the house films made in the 1950s.

\section{THEN AND NOW}

All of the above characteristics must be placed in the context of the times. Britain was a very different place back then. It still saw itself as a major player on the world stage, certainly in terms of military might, international affairs, manufacturing and trade. Society in general was conservative in the extreme and relatively unchanged despite the traumas of WWII. It was a far cry from the diverse, multicultural, relatively tolerant, relatively humble country of today. Everything changed in 1963 with one of the most defining moments in British social history. The mother of all scandals, the so-called 'Profumo affair' marked the divide between the old and new worlds and the country would never view itself in quite the same way again. That rather vague concept known as 'The Establishment' was questioned in a way never seen before and the widely-held public perception of people in power as always acting unimpeachably and with the highest moral standards began being questioned. As the UK emerged from the whirlpool that was the 1960s, during which time so much changed, it was clear that the professions would have to change too, and change they have, so much so that if we examine the defining characteristics outlined above, hardly anything (certainly as far the dental profession is concerned) has remained wholly untouched. Some of these changes are discussed below:

\section{Education}

Education and training remains at the core of the dental profession and one of the most 
positive developments of recent years is the growing importance attached to ongoing post-qualification training. Fundamental, rapid advances in oral healthcare have resulted in a far greater emphasis being placed upon scientific, evidence-based treatments and keeping up-to-date with all these changes makes dental education a vital and continuing process, demanding more commitment from the dental practitioner than in the past, when the pace of change was much slower and when many a dentist could seemingly pass from graduation to retirement virtually without ever learning anything new. In 2002, and in recognition of this need for dentists to stay current 'as a professional duty', the GDC implemented its programme of compulsory continuing professional development (CPD), with CPD defined as: 'Study, training, courses, seminars, reading and other activities undertaken by a dentist, which could reasonably be expected to advance his or her professional development as a dentist."

The advent of compulsory core subjects in 2007 further strengthened this approach. It is clear that the dentist's role is changing and the modern professional has so much more to contend with than counterparts say 20 or 30 years earlier. This was clearly articulated in a letter published in this journal ${ }^{9}$ in the spring of 2013 in which the author, a retiring dentist, rather cynically observed: 'Forty years ago my job description was dental surgeon; today my job title is performer and provider of primary dental care for the local PCT, lead in child protection, lead for crossinfection control, radiological protection supervisor, health and safety supervisor, fire warden, lead for information governance, lead for staff training, and environmental cleaning operative.'

What is perhaps of greater concern is the level of preparedness for professional life of new graduates. Considerable effort has been spent trying to ensure that today's new graduates are more rounded 'healthcare professionals', better able to provide total patient care as opposed to what is now viewed as the piecemeal drill-and-fill dentistry of yesteryear. The GDC's document The first five years ${ }^{10}$ identifies the three levels of expertise desirable in new graduates. The highest of these requires the graduate to have 'sound theoretical knowledge and understanding of the subject together with an adequate clinical experience to be able to resolve clinical problems encountered, independently, or without assistance.' For example, students are expected to be competent at 'a range of procedures in restorative dentistry, including amalgam and tooth-coloured restorations, endodontic treatments of single- and multi-rooted teeth, anterior and posterior crowns, post crowns, simple bridges and partial and complete dentures.' The current opinion of those charged with providing undergraduate dental education was articulated in an excellent review of the state-ofmind of dental graduates and undergraduates undertaken by Divaris et al. ${ }^{11}$ who observed 'Of course, it is not expected that undergraduates will have achieved clinical excellence at graduation. Nevertheless their educational experiences must have equipped them with the necessary self-assessment ability, clinical reasoning, initial self-confidence and preparedness for professional life and the safe independent practice of dentistry. The difficulty with this statement is that while dental educationalists might not expect "clinical excellence at graduation' the public at large, not unreasonably, probably do and would assume that clinical excellence goes handin-hand with an ability to practise safely. This is an opinion echoed by many of those employing recently qualified dentists and even recognised by some graduates themselves. Indeed, Divaris et al. also acknowledged the number of recent graduates who in their words felt "unprepared or insecure as independent clinical practitioners, even though they may have had adequate clinical training.' ${ }^{11}$ Indeed some newly-qualified dentists feel themselves that this lack of self-confidence is so severe that they suffer so-called 'burn-out' at a very early stage in their professional development. ${ }^{12}$

\section{Self determination}

While the GDC continues to control entry to the dental registers, aims to assure the quality of dental education, sets standards of practice for dental professionals and investigates complaints from the public about lapses of standards its autonomy is nevertheless much reduced in comparison to when it was established in 1956. The decision-making process is now overseen by a 12 member council made up of 6 lay and 6 dental professional members, a far cry from the 4 lay members out of 43 in 1956. The GDC has also had to bow to outside pressure on various occasions down the years. Three such examples are discussed below.

\section{Removal of restrictions on advertising}

Until the mid-1970s, virtually all professional service providers such as doctors, dentists, lawyers and accountants were prevented from advertising by restrictions imposed upon them by the various professions' own regulatory bodies. This was a worldwide phenomenon and the primary reasoning behind these restrictions was equally universal and consistent, namely that such advertising was deemed to be unprofessional (by professionals themselves) and would lower the status of the professions in the eyes of the public. However, by the late 1970s it was clear that, in the US at least, all professions were coming under increasing pressure to deregulate, paradoxically through public as well as governmental pressure. This move towards deregulation can be traced to seminal judicial interpretations concerning commercial free speech ${ }^{13,14}$ and restraint of trade by professional organisations. ${ }^{15}$ These effectively removed any constraints on marketing imposed by a whole range of professional associations and as a result, by 1983 , American dentists were allowed to advertise their services freely to the public.

Once the precedent had been set by the US authorities, a number of other countries followed suit and began to embrace dental advertising, including the UK where the earliest discussions in this area stemmed from a Monopolies Commission report looking into the restrictive practices adopted by a variety of professions. ${ }^{16}$ The commission found numerous examples, which they concluded were against the public interest. Among these were the constraints relating to marketing, which, by denial of information concerning individual practitioners and practices, limited consumer choice or made the optimum selection difficult or impossible. The main wave of deregulation began when the British Medical Association ${ }^{17}$ declared that: 'Patients are entitled to be given comprehensive, detailed and accurate information about medical services available to them. Doctors working within the National Health Service as opposed to private practice have particular obligations imposed on them by their terms of service by which they must provide both personal, professional and practice information.'

The dental profession quickly followed suit and, by 1988 , the only restrictions applied to advertising were those applicable to all advertising, namely that it be "truthful, decent and honest'.

While the relaxation of advertising regulations did not see the dental professional descend into the gutter as many had feared (in fact the profession has boomed in the intervening 25 years) there are very real fears that the pendulum has swung too far in the opposite direction and that in an increasing number of cases, an overly-aggressive stance is being taken by some dentists and dental groups, especially when it comes to the marketing of cosmetic services. For example, a comprehensive study carried out by the 2012 Office of Fair Trading (OFT) in $2012^{18}$ drew attention to the fact that many patients were put under pressure by their dentist to sign up 
to advertised payment plans and as a result, these patients are denied the opportunity to make active, informed decisions regarding how they pay for their dental treatment and even what treatment is actually required. The study found that a staggering $82 \%$ of dental patients who received a course of dental treatment that incurred a charge did not receive a written treatment plan. Among a raft of suggestions made in the Department of Health's Review of the regulation of cosmetic interventions ${ }^{19}$ published in 2013 were the following:

- Banning free consultations for cosmetic surgery so that people don't feel obliged to go through with surgical procedure

- Ensuring consultations are with a medical practitioner and not a sales adviser

- Imposing tighter restrictions on advertising including banning two-forone, time limited deals and cosmetic surgery as competition prizes.

\section{Direct access}

Another example of change being imposed upon the profession from outside concerns the thorny issue of direct access. Up until March 2013, every member of the dental team had to work to the prescription of a registered dentist. This meant that patients had to be seen by a dentist before being treated by any other member of the dental team. Direct access represents a complete volte face by the GDC and clearly contradicts earlier GDC initiatives. For example, the following statement appeared in a 1998 report published by The Dental Auxiliaries Review Group, which was set up by the GDC to explore the future role of ancillary dental staff; 'dental care in the next century will be provided by a multi-skilled team comprising members of the dental profession and professions complementary to dentistry, all led by a dentist ${ }^{20}$ Direct access appears to have arisen through pressure applied by the OFT and is being vehemently opposed by the British Dental Association (BDA) whose view was very clearly declared in a statement ${ }^{21}$ released on the date the decision to proceed with direct access was announced: 'This is a misguided decision that fails to consider best practice in essential continuity of care, patient choice and cost-effectiveness, and weakens team working in dentistry, which is demonstrated to be in patients' best interests. Dental hygienists and therapists are highly-valued and competent members of the dental team, but they do not undertake the full training that dentists do and on their own are not able to provide the holistic, comprehensive care that patients need and expect. Our fear is that this could lead to health problems being missed in patients who choose to access hygiene and therapy appointments directly.'

\section{Care Quality Commission}

The Care Quality Commission (CQC) was established in April 2009 and quickly deemed that from April 2011 all primary dental services would have to register with the CQC. Registration is a legal licence to operate and, put simply, if dental practices are not registered then they will not be able to provide services. In order to become registered the provider must be deemed to be 'compliant' that is, must show that the service offered does indeed meet essential standards of safety and quality. At first sight this seems to be a sensible development and yet the introduction of CQC has, however, been far from smooth and certainly has not been welcomed with any great enthusiasm by the profession, many of whose members view it as yet another unnecessary, centrallyimposed, ill-conceived, burden. A mood captured by Dentistry magazine, which reported that: 'The introduction of compulsory registration with the CQC... triggered howls of protest from many dentists. ${ }^{22}$

\section{Discipline}

The difference between the modern dental profession and its 1950s counterpart is nowhere more apparent than in the number of complaints against practising dentists. Whether this is because of a moral decline in the profession, or because modern dentistry is so much more complicated nowadays that more things can go wrong or possibly because the public are more inclined to complain in these modern times, the truth is likely to contain elements of all three of these. What is undeniable is that in recent years there has been a staggering growth in the number of disciplinary cases being heard by the GDC. In response, in 2005, the GDC published Standards for dental professionals, ${ }^{23}$ effectively a road-map detailing the responsibilities of a dental professional.

This was updated in 2013 and appeared as the subtly re-named Standards for the dental team ${ }^{24}$ featuring the following nine key principles:

Put patients' interests first.

- Communicate effectively with patients

- Obtain valid consent

- Maintain and protect patients' information

- Have a clear and effective complaints procedure

- Work with colleagues in a way that serves the interests of patients

- Maintain, develop and work within your professional knowledge and skills
- Raise concerns if patients are at risk

- Make sure your personal behaviour maintains patients' confidence in you and the dental profession.

The emphasis in this document on 'softer skills' and a patient orientation is clear and on its launch GDC Chief Executive Evlynne Gilvarry observed:

'Patients have told us clearly what they expect when they seek dental treatment. The new standards reflect those expectations and guide the dental profession in meeting them.'

The GDC clearly hope that this initiative will go some way to quelling the rising number of disciplinary cases being heard. The figures speak for themselves. For example, in 1987 the total number of hearing days scheduled by the GDC amounted to around 20. By 2012 this had mushroomed to more than $1,019 .{ }^{25}$ It is as though the profession has sailed into the eye of a perfect storm. Take for example, the thorny issue of the 'cosmetic makeover'. Modern ceramic veneering techniques allow dentists to transform the appearance of dentitions almost at a stroke. This possibility is clearly quite appealing to many members of the public who are prepared to pay large sums of money and place their trust in the dentist to carry out appropriate work and to do it well. In the case of the unscrupulous dentist it is easy to see how he/she might oversell the advantages of these techniques and at the same time say little of the possible drawbacks. Even for well-meaning, ethical dentists such cases are problematic. Laminate veneers are extremely techniquesensitive and achieving an aesthetic, longlasting result, which in turn causes minimal damage to underlying tooth structure, takes great technical skill and meticulous treatment planning, a large part of which involves understanding the patient's motivations and expectations. It is hardly surprising that in many cases things go awry. Little wonder then that Dental Protection Ltd recently warned its members that in terms of litigation; 'Multiple veneers placed electively for cosmetic reasons (that is, in the absence of pathology) - the so-called smile make-over - are the area of greatest risk. ${ }^{26}$ One of the most substantial reviews of the laminate veneer technique ever carried out Burke and Lucarotti ${ }^{27}$ concluded: 'These results give a strong message to all clinicians who raise a rotating bur to a tooth, namely that, despite their intended minimal invasiveness, the tooth prepared for a veneer becomes compromised and may be replaced by a more invasive restoration which, in turn, increases the likelihood of pulpal involvement and/or tooth fracture.' 
And yet we seem to be bombarded from all corners by over-inflated statements promising a great deal with no mention of potential downsides. The same could be said about implants, orthodontic treatment, the list is almost endless. We always need to remain focused on basic fundamentals. This means listening to patients, thorough diagnosis and treatment planning, only performing treatment within one's own competencies, knowing when to refer, always looking out for the patient's best interests rather than 'what's in it for me'. These are the hallmarks of professionalism in 2013 just as much as they were when the GDC was founded over 50 years ago.

If a dentist cannot behave in this way then he/she does not deserve to be called a "professional' and should be expelled, surely it is as simple as that.

\section{STATUS}

It is probably fair to say that dentists are still held in high regard by the rest of society. A dentist's reputation is rather like a potted plant in that it requires continual attention and maintenance. At the end of the day one's reputation is priceless since it reflects the perception others have of you, not just your patients, but also staff members and other dentists. It is the very essence of what it is to be professional. It implies a certain gravitas, an authority which leads to great respect. Unfortunately, this seems to be lost on more and more members of the profession who see dentistry as just another job. We certainly do not need to go back to the days when the dentist was an extremely paternalistic figure who decided what was best for the patient. On the other hand it is dangerous to swing too far the other way to a state of affairs where the patient, fuelled by information from the internet, attempts to dictate treatment. As the old saying goes 'A little knowledge is a dangerous thing'. Surely there is a middle ground upon which a consensus is agreed between dentist and patient only after the views and opinions of both parties have been openly aired and discussed. All of this is entirely compatible with dentistry as a business, but this should be viewed very specifically as a professional practice that offers a unique service, one that is different in so many ways from most other businesses. We simply cannot treat dentistry as a commodity because when we do the consumer will simply find the cheapest provider, either in the UK or abroad.

\section{CONCLUSION}

While it is quite reasonable to expect the behaviour and attitudes of dentists to move with the times, the authors feel strongly that some of the more recent attitudinal shifts and changes within the profession have been and will continue to be detrimental. We are of the opinion that:

1. In general terms dentistry is in danger of losing its intangible air of professionalism. This is something that has been built up over many decades and which we throw away at our peril. For example, the modern professional should of course be kind, approachable, empathic and understanding but this needs to be tempered by a certain gravitas and even a degree of emotional detachment. It is our opinion that most patients would prefer their dentist to be friendly but not their friend, a subtle but very clear and important distinction. Such impartiality allows the practitioner to maintain an objective view of any given clinical situation. This is even more important nowadays in an age where patients can access all kinds of information and advice from a wide variety of sources and might feel that they can, as a result, dictate the treatment they receive. We are very much in favour of patients being actively involved in the whole treatment process but this must never be at the expense of ensuring that all work undertaken is appropriate and necessary. To do otherwise would, in our view, quite simply be unprofessional

2. The degree to which patients gauge our levels of professionalism is the sum of all the so-called 'moments of truth' that arise not just with us as dentists but also through every interaction with each member of the team. Dentistry is increasingly a team effort and more than ever we believe that all team members should be encouraged to feel that they too have a responsibility to act in a professional manner. Sadly, it is our opinion that many dentists still view their team as subordinates, do not give enough thought to their recruitment and do not invest sufficiently in them. The end result is a lack of motivation that often manifests itself as 'presentism' that is, the person is there in body but not in spirit. This is never more damaging than the situation in which a disengaged team member resorts to the use of social media during working hours - surely one of the most unprofessional things they could possibly do and one which in our opinion should be a disciplinary matter

3. Of particular concern to us is the fact that more and more promotional material seems to undermine our professional status, treating dentistry as a commodity and not as a highly specialised personal service. The genie is out of the bottle as far as advertising is concerned but this does not mean anything less than the recommended 'legal, decent, honest and truthful,' should be tolerated. What perhaps concerns us most is that while much of what is out there (special offers, loss leaders and so on) does not specifically contravene these guidelines the underlying tenor is often far from desirable. All of this is a reflection of a mind-set that dentistry is nowadays more a business than a profession. A business-like attitude is important but this needs to fit hand in glove with a professional one. It is our view that money should not be the sole motivation in any business. Offering excellent professional service comes first and financial benefit will follow as a natural consequence. Unfortunately there seems to be a growing number in the profession who put financial gain ahead of core professional values

4. We believe that young dentists in particular need to understand that they are 'on show' all the time and that once they leave work they do not cease to be a professional. Images posted on social media have a nasty habit of cropping up in the most unexpected places. We are by no means recommending puritanism, just realistic caution. We would venture to suggest that professional practice is a more clearly defined requirement of dental foundation training

5. In the same vein we believe that it is vital that overseas dentists working in the UK share and are able to demonstrate that they understand what it means to be a professional in the context of UK dental practice. Perhaps there should be a requirement that all non-UK trained dentists have to demonstrate an understanding of the meaning of professionalism in the context of UK dental practice as part of being allowed to practise here

6. Finally, dentistry is, more than ever, a team game and it is imperative that professionals complementary to dentistry, namely dental nurses, dental technicians, dental therapists, dental hygienists, orthodontic therapists and clinical dental technicians understand that the status which goes hand in hand with registration with the GDC also brings with it considerable professional responsibilities. 
In our view it is imperative that dentistry remains a profession, at its core the concept of doing the right thing at the right time and when no one is watching. All dentists should understand what it means to be a professional and must pay heed to the underlying set of values and codes that distinguish what we do from most other vocations and which we must not ignore. We should take all steps to safeguard these precious assets, namely our collective professional status and our individual reputations, even if this means reigning in some of the more 'modern' aka dubious modus operandi of some practitioners.

1. Raach $J$ H. English medical licensing in the early seventeeth century. Yale J Biol Med 1944

16: 267-288.

2. Medical Act 1858. UK Statute Law database. Official text as originally enacted available at http://www. legislation.gov.uk/ukpga/Vict/21-22/90/contents/ enacted (accessed February 2014). UK Statute Law database.

3. Dentists Act 1921. Official text as originally enacted. UK Statute Law database.
4. Acland S F Quoted in Basker R M. GDC - the first 50 years. pp 1. London: General Dental Council, 2006

5. Final report of the Inter Departmental Committee on Dentistry. HSMO, 1946.

6. Dentists Act 1956 Official text as originally enacted. UK Statute Law database.

7. Royal Commission on Medical Education 1965-1968 London: Her Majesty's Stationery Office, 1968.

8. General Dental Council. Compulsory continuing professional development (CPD). London: GDC, 2003.

9. Austin M. Demise of the single-handed practitioner. Br Dent J 2013; 214: 218

10. General Dental Council. The first five years. The undergraduate dental curriculum. London: GDC, 1997.

11. Divaris K, Barlow P J, Chendea S A et al. The academic environment: the students' perspective. Eur J Dent Educ 2008; 12: 120-130.

12. Gorter R C, Storm MK, te Brake J H, Kersten H W, Eijkman M A. Outcome of career expectancies and early professional burnout among newly qualified dentists. Int Dent J 2007; 57: 279-285.

13. Virginia State Pharmacy Board v. Virginia Citizens' Consumer Council. 425 US 748, 1976.

14. Bates v. State Bar of Arizona. 433 US 350, 1977

15. Goldfarb v. Virginia State Bar. 421 US 773, 1975.

16. Professional services: a report on the general effect on the public interest of certain restrictive practices so far as they prevail in relation to the supply of professional services. London: Monopolies Commission HMSO, 1970.
17. British Medical Association. Guidelines to doctors on advertising. London: BMA, 1991.

18. Office of Fair Trading. Dentistry, an OFT market study. London: OFT, 2012.

19. Keogh B. Review of the Regulation of Cosmetic Interventions. London: Department of Health, 2013.

20. General Dental Council Dental Auxiliaries Review Group. Professionals complementary to dentistry. A consultation paper. London: GDC, 1998.

21. British Dental Association. Press release: direct access decision misquided says BDA. London: BDA, 2013.

22. Merrick R. CQC measures 'challenging' for dentists. Dentistry 2013. Online article available at http:// www.dentistry.co.uk/news/cqc-measures-challenging-dentists (accessed February 2014).

23. General Dental Council. Standards for dental professionals. London: GDC, 2005.

24. General Dental Council. Standards for the dental team. London: GDC, 2013.

25. General Dental Council. Annual report and accounts 2012. London: GDC, 2013.

26. Kelleher M. Decisions, decisions. Managing restorative dilemmas and patient expectations. 2011. Online

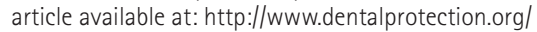
adx/aspx/adxGetMedia.aspx?DocID=9b3e649a-7f074b6b-926c-66eea4f42bd1 (accessed April 2014).

27. Burke F J T, Lucarotti PS. Ten-year outcome of porcelain laminate veneers placed within the General Dental Services in England and Wales. J Dent 2012; 40: 886-895. 